\title{
A QUEM RECORRER? - O SERVIÇO DE PRONTO SOCORRO DO HOSPITAL DAS CLÍNICAS DE SÃO PAULO, 1930-1950
}

\author{
Where to look for help? - The Emergency Medicine \\ Service at the São Paulo Hospital of Clinics, 1930-1950
}

\author{
André Mota*
}

\begin{abstract}
RESUMO
O artigo em pauta estuda a constituição do Serviço de Pronto Socorro do Hospital das Clínicas de São Paulo. Criado em 1944 como resposta às demandas vividas pela cidade, a partir da explosão populacional advinda do processo migratório entre os anos de 1930-1950, o Serviço teve que lidar com os contratempos trazidos, tanto pela administração municipal e seu gerenciamento no campo hospitalar, como as próprias contradições de uma cidade em franca expansão populacional e sem controle. Nesse sentido, busca-se apresentar o projeto arquitetado e formulado pelos professores da Faculdade de Medicina USP, bem como a indicação de tais contratempos em seus primeiros anos, formulada pelo Hospital das Clínicas como também pelas notícias da imprensa local, envolvendo a complexidade da assistência hospitalar da capital paulistana.
\end{abstract}

Palavras chave: Assistência médica, Pronto Socorro, Instituição hospitalar, Imprensa local paulistana

\footnotetext{
ABSTRACT

This paper studies the constitution of the Emergency Medicine Service at the São Paulo Hospital of Clinics. The Service was created in 1944 in response to the city's needs arising from the population explosion caused by the migratory process between

* Historiador, Professor do Departamento de Medicina Preventiva - FMUSP e Coordenador do Museu Histórico - FMUSP E-mail para contato: a.mota@ fm.usp.br
} 
the $1930 \mathrm{~s}$ and $1950 \mathrm{~s}$, and it had to deal not only with the adversities caused by the municipal administration and its hospital management, but also with the contradictions of a rapidly and uncontrollably expanding city. With this in view, we aim to present (1) the project formulated by professors of the USP School of Medicine, and (2) the inventory of the aforesaid adversities, in their early years, as reported by both the Hospital of Clinics and the local press, showing the complexity of hospital care in the city of São Paulo.

Keywords: Medical care, Emergency medicine, Hospital institution, São Paulo's local press

A historiografia brasileira preocupada com a saúde pública em seu vínculo com os serviços de assistência vem ganhando espaço dos estudos atuais. ${ }^{1}$ No caso paulista da primeira metade do século $\mathrm{XX}$, tanto as instituições governamentais quanto as sociedades civis passaram a ganhar destaque dos pesquisadores ${ }^{2}$, assinalando uma rede de interesses e temas que se cruzavam no sentido de responder às intempéries que avançavam nas áreas urbanas e rurais do Estado, explicitando tantos as doenças que abatiam a sua população, das consideradas mais antigas às inéditas, como as estratégias que fossem consideradas capazes de barrar o impedimento do desenvolvimento do Estado. Assim, acompanhar suas localidades se tornou obrigatório no sentido de reconhecer questões específicas, já que as balizas capitalistas, ao passar ou não por uma determinada localidade, delimitariam os impactos ou não da chegada dessas instituições e seus representantes. $^{3}$

Nesse estudo, faremos uma incursão bastante precisa, ou seja, as preocupações se darão sobre a capital paulista, ao se voltar para o tema da assistência hospitalar em torno do pronto atendimento nos

1 SANGLARD, Gisele [et.all] Filantropos da nação: sociedade, saúde e assistência no Brasil e em Portugal. Rio de Janeiro, FGV Editora/Faperj, 2015.

2 MOTT, Maria Lucia e SANGLARD, Gisele (orgs) História da Saúde em São Paulo, Rio de Janeiro/São Paulo, Fiocruz/Manole, 2011.

3 Acompanhar discussão sobre as especificidades municipais paulistas em sua relação com as instituições médicas e de saúde pública em: MOTA, André e MARINHO, Maria Gabriela S.M.C. Práticas médicas e de saúde nos municípios paulistas: a história e suas interfaces. Coleção Medicina, Saúde \& Historia,vol.1, São Paulo, EDUFABC/CD.G Casa de Soluções e Editora, 2011. 
casos de urgência. A intenção será a de apresentar esse serviço criado em 1944 pelo Hospital das Clínicas da Faculdade de Medicina da Universidade de São Paulo em seus primeiros anos. Isso porque, a assistência hospitalar na cidade de São Paulo mostraria o hiato entre a complexidade da assistência demandada e o serviço oferecido, que se complexificou com o processo migratório que havia sido estimulado pelo governo paulista, a partir dos anos de 1930, quando milhares de homens e mulheres foram atraídos à cidade, tendo sua chegada se dado sem estrutura urbana compatível, nem de seus serviços de saúde preparados para recebê-los.

\section{A cidade de São Paulo e o processo migratório dos anos de 1930-1950}

Na virada do século XIX para o XX, a vinda de novos povos implicou uma explosão demográfica paulistana e, aos poucos, logrouse uma confusa acomodação entre imigrantes e nacionais. Os anos 1930 aprofundaram essa perspectiva, quando a população estabelecida assistiu a um novo e súbito aumento populacional, em função do processo migratório, agora essencialmente interno e notadamente de grupos vindos da Bahia, de Pernambuco, de Alagoas, do Sergipe e da porção setentrional de Minas Gerais. Para compreender esse deslocamento, é preciso sublinhar, particularmente, dois momentos do processo. ${ }^{4} \mathrm{O}$ primeiro ainda é relativo à crise de

4 No caso da cidade de São Paulo, foi do estilhaçamento das relações passadiças e de sua remontagem em novos contextos com suas representações e imagens do progresso sem limites que se configurarão a chegada de novas gentes, a tomada de terras e formas de viver de uma "outra" cidade, com muita marcação a partir da década de 1930, ganhando dimensões metropolitanas. Com uma racionalidade cada vez mais complexa, vivendo mudanças que acabam por construí-la e degradá-la, a capital paulista segue com sua estruturação administrativa fundada em limites orçamentários, ineficácia administrativa e paralisia diante da intransigência das manobras especulativas. Acompanhar o estudo desse processo de urbanização paulistano em: SANTOS, Milton. Técnica, espaço, tempo: globalização e meio técnico-científico informacional. São Paulo, Hucitec, 1994. 
1929 e às necessidades da produção cafeeira no estado de São Paulo, quando:

ao adquirir os estoques excedentes, construir uma infraestrutura de armazenamento do produto e elaborar uma política de desvalorização da moeda nacional, o Estado tornava-se sócio dos cafeicultores, socializando, assim, as perdas do setor por meio do encarecimento das importações e do endividamento externo. Entretanto, depois da grande crise, o governo teve que tomar medidas adicionais para manter a viabilidade econômica do setor. Essas políticas foram, basicamente, a queima de parte do estoque de café adquirido pelo Estado e o subsídio para contratar trabalhadores (desta vez, migrantes nacionais) com o fito de sanar o problema da "falta de braços" nos cafezais paulistas. ${ }^{5}$

O governo estadual subsidiou o processo migratório, o que acabou, por um lado, concorrendo para a recuperação da cafeicultura e, por outro, promoveu uma acumulação de força de trabalho industrial das grandes cidades, sobretudo, na de São Paulo. Paulatinamente houve a diminuição da produção cafeeira e uma crescente diversificação de culturas no oeste paulista como o plantio de laranja, cana-de-açúcar, feijão, milho e algodão, o que permitiria o deslocamento de parte dessa população para as grandes cidades, iniciando a formação de uma reserva de trabalho para as indústrias e setor de serviços:

o então governador do estado de São Paulo, Armando de Salles de Oliveira, por meio da Secretaria da Agricultura, reeditou, em 1935, uma política de estímulo à migração de trabalhadores nacionais, baianos e mineiros em sua

5 SILVA, Uvanderson Vitor. Velhos caminhos, novos destinos: migrantes nordestinos na Região Metropolitana de São Paulo, Dissertação de Mestrado, Departamento de SociologiaFFLCH-USP, 2008. p. 19. 
maioria, em direção às lavouras do interior. Os deslocamentos desses trabalhadores eram realizados com subvenção oficial por meio de contrato com empresas particulares de imigração e colonização, e ficava a cargo do Estado o pagamento das passagens e do transporte de bagagens dos migrantes [...]. Em 1939, ocorre uma mudança significativa na política migratória do estado que desarticulou os interesses das companhias privadas: a criação da Inspetoria de Trabalhadores Migrantes (ITM). Essa Inspetoria possuía uma estrutura própria de agentes contratantes, com escritórios nas cidades de maiores influxos de migrantes interessados em entrar no estado de São Paulo. ${ }^{6}$

Entre 1935 e 1939, dos 285.304 trabalhadores e trabalhadoras que entraram na Hospedaria dos Imigrantes, 96,3\% eram brasileiros. Um segundo movimento, que de alguma forma deu sequência ao processo, posto que não cessou a vinda de migrantes, mas a intensificou a partir do pós-guerra, ocorreu com o projeto nacionaldesenvolvimentista de Getúlio Vargas, aprofundando-se na planificação de Juscelino Kubitschek, nos anos 1950, com alto investimento no parque industrial brasileiro. Essa nova configuração de atividades produtivas industriais aumentou as oportunidades de emprego nos grandes centros urbanos e no setor industrial paulista, região que abrangia a capital e cidades vizinhas, como o chamado $\mathrm{ABC}$ paulista ${ }^{7}$, criando essa nova demanda:

diferentemente do período anterior, o Estado não mais subvencionaria o recrutamento e o deslocamento da força de trabalho que se dirigia à metrópole paulista e carioca. Tratava-se de uma "migração espontânea", em que os próprios migrantes arcariam com as despesas da empreitada [...] realidade marcada pela desapropriação,

6 Idem

7 Cidades industriais localizadas na região metropolitana de São Paulo: Santo André, São Bernardo do Campo e São Caetano do Sul. 
pela seca, pela desestruturação do campesinato; enfim, não se tratava apenas de uma alocação ótima dos fatores de produção do espaço, mas sim de um processo social cuja base estaria marcada por contradições próprias de um novo modelo de desenvolvimento econômico cujo eixo estruturador era a indústria moderna. ${ }^{8}$

Com o impacto desse contexto, a atração de trabalhadores recrudesceu, tomando a dimensão de um verdadeiro êxodo rural, estimulada, sobretudo, pelas secas da região nordestina de 1951-53 e a de 1958. Entre 1951 e 1955, o Departamento de Imigração e Colonização registrou a entrada de 762.707 migrantes na cidade, representando um crescimento de aproximadamente 60\%. Com isso, o tamanho do município triplicou, enquanto, no mesmo período, a população nordestina cresceu dez vezes, empregando-se em massa nos vários ramos da indústria e de serviços, em franca expansão na Região Metropolitana de São Paulo. ${ }^{9}$

Nessa conjuntura, o governo paulista parecia indiferente ao que ocorria, inclusive à infraestrutura necessária para recebê-los institucionalmente, como foi o caso da Hospedaria dos Imigrantes, oficialmente responsável por acolher e distribuir as famílias entre as regiões do estado onde houvesse necessidade de mão de obra. Em 1952, o jornal $O$ Estado de S.Paulo voltou a falar das levas de nordestinos que entravam na capital sem nenhum controle. Chegariam doentes e subnutridos, com conjuntivite, diarreia e tuberculose, resultado da longa viagem realizada e a Hospedaria, dizia-se, quase não prestava os serviços adequados:

o serviço médico da Hospedaria de Imigrantes é o mais precário possível. Não dispõe de nada, absolutamente nada, a não ser da boa vontade e dedicação de seus profissionais, que se encontram na dura contingência de

8 FONTES, Paulo. Um nordeste em São Paulo: trabalhadores migrantes em São Miguel Paulista 1945-1966, Rio de Janeiro, EdFGV, 2008.p. 26.

9 Idem 
limitar o exercício de suas funções à verificação perfuntória do aspecto geral dos trabalhadores nordestinos que para lá caminham, na alarmante média diária de 1.500 pessoas. ${ }^{10}$

O cenário narrado pela imprensa local emoldurava a realidade da miséria provocada, sobretudo, pela falta de moradia que se ampliava dia a dia por toda a cidade:

é a miséria numa casinha tosca do Ipiranga. É a miséria em plena Praça Ramos de Azevedo, onde um sofredor anônimo das ruas dorme no cimento frio. É a miséria a exigir que crianças esqueléticas procurem resto nos monturos. É a miséria na favela, miséria num banco da Praça da República porque a infeliz criatura não conseguiu vaga no albergue superlotado. É a miséria na Vila Maria, onde uma sexagenária anda à cata de qualquer lixo para poder comer! É assim a vida na capital dos tubarões e das filas. Esperam-se dias melhores. A esperança alimenta a população pobre de São Paulo. ${ }^{11}$

Segundo o levantamento da moradia operária em 1946, havia na capital 1.916 famílias, $47,02 \%$ das quais nas chamadas habitações coletivas - os cortiços -, o que agravava a situação e obstava os resultados das ações das instituições assistenciais de saúde. Segundo levantamento realizado no período sobre as condições de habitação e medidas de saneamento (água potável, rede de esgoto e destinação do lixo), a situação era de precariedade:

quanto a rede de esgotos, até 1953 , cobria apenas $2 \%$ da área total do município, e menos de $50 \%$ dos prédios da zona urbana estão ligados à Rede. A situação de esgotos

10 O Estado de S. Paulo, São Paulo, 18/03/1952. p.8.

11 A Gazeta, São Paulo, 08/05/1947. p.5. 
sanitários não satisfaz e tem caído face ao crescimento da população e extensão da área a atender. ${ }^{12}$

Dessa forma, ampliava-se a área da cidade, atingindo proporções incomuns, acrescentando-se a ideia da "influência exterior da cidade" sobre o semideserto que havia em torno dela, com a multiplicação das indústrias agrárias e do carvão de lenha e dos locais para diversão e recreio, como os bairros de Santo Amaro e da Cantareira. A esse desenvolvimento considerável não podia deixar de corresponder uma extrema intensificação da existência urbana, que marcaria sua fisionomia. ${ }^{13}$ A formação de novos bairros ganha o interesse das elites, por manter isolada e invisível uma população indesejada, e significa lucro fácil para os especuladores por meio de lotes clandestinos. Foi uma fase de expansão dos loteamentos das zonas periféricas destinados à autoconstrução e com regulamentação precária:

um gigantesco universo de clandestinidade, superando largamente os espaços da legalidade: bairros sem registro, ruas sem nome, casas sem número, moradores sem documentos. As únicas entidades legalizadas eram as chamadas sociedades amigos de bairro, que negociavam com políticos a lenta conquista de melhorias, do calçamento à escola, da iluminação pública às linhas de ônibus ou à coleta de lixo. ${ }^{14}$

Indo além, se até então as favelas eram em número suficientemente baixo para passar quase despercebidas na urbe, entre

12 CASTRO, Paulo de Carvalho. Contribuição para o estudo da administração dos serviços locais de higiene infantil na Capital do Estado de São Paulo, São Paulo, Tese de Livre Docência, Faculdade de Saúde Pública-USP, 1958. p.14.

13 BRUNO, Ernani Silva. História e tradições da cidade de São Paulo. 4. edição, vol.3, São Paulo, Hucitec, 1991. p.183.

14 REIS, Nestor Goulart. Dois séculos de projetos no Estado de São Paulo, vol.III (1930-2000), São Paulo, Edusp/Imprensa Oficial, 2004. p.27. 
1930-70, sua presença ganha a atenção das autoridades municipais, exigindo intervenções e herdando, desde suas origens, os estigmas que cercavam os cortiços, mesmo que seu surgimento não estivesse relacionado a nenhum movimento organizado de invasões. Muito pelo contrário, é bom lembrar que as primeiras favelas paulistanas eram ocupações consentidas ou ainda estimuladas pela prefeitura. A sua proliferação diria da transição que a cidade viveria, sem preparação lenta ou adaptativa, mas, ao contrário, de forma veloz e violenta, absorvendo muitos desses grupos que chegavam sem alternativas de vida ou de trabalho.

Em seu instigante trabalho sobre a "invenção" das favelas cariocas, Valladares atentou não apenas a seu surgimento, mas a toda uma série de definições que nasceriam das relações estabelecidas entre a população e as políticas urbanas e imobiliárias, ganhando e perdendo elementos explicadores do lugar e também de seus moradores. Entre elas, algumas parecem ganhar sentido menos local e mais nacional, e seriam:

as respectivas representações que aparecem fortemente estruturadas pelas preocupações políticas relativas à consolidação da jovem República, saúde da sociedade e entrada na modernidade. A favela pertence ao mundo antigo, bárbaro, do qual é preciso distanciar-se para alcançar a civilização (...) um 'outro mundo', muito mais próximo da roça, do sertão, 'longe da cidade'... ${ }^{15}$

No entanto havia um problema adicional diretamente ligado aos serviços de saúde em São Paulo, que além de seguir ainda o Código Sanitário de 1918, formulado pelo médico Arthur Neiva, e depois reformado por Geraldo de Paula Souza em 1925, também refletia as mudanças políticas trazidas pelo populismo getulista:

15 VALLADARES, Licia do Prado. A invenção da favela: do mito de origem a favela.com. $6^{\mathrm{a}}$. reimpressão, Rio de Janeiro, EdFGV, 2015.p.36. 
depois de 1930, não se estabeleceu uma orientação planejada de saúde pública para a cidade e nem para o Estado. A falta de continuidade manifestou-se no próprio período de permanência dos secretários responsáveis pela pasta e dos diretores do Serviço Sanitário, depois, Departamento de Saúde Pública. Em média, os secretários permaneceram no cargo 203, 81 dias e os diretores de saúde pública 312, 21 dias entre 1930-1947 (...) um processo de descentralização e pulverização de serviços marcou a estrutura de organização de saúde pública que acabou por confundir e inviabilizar a coordenação das práticas sanitárias. Esse processo refletia não somente $\mathrm{o}$ crescimento urbano $\mathrm{e}$ populacional, mas também as demandas e pressões políticas por cargos e empregos públicos. ${ }^{16}$

Seria desse contexto complexo vivido pela cidade de São Paulo, que seus serviços de médicos e de saúde começaram a ressentir, cada vez mais, os limites de suas ações. Se as medidas executadas na virada do século XIX já demonstravam as contradições de fazer de seu território a civilidade esperada e espelhada sanitariamente, haveria uma crise maior, aguçada por novos contextos e demandas, exigindo esforços adicionais. Esse foi o caso da chegada do Hospital das Clínicas ao apresentar um grande projeto de pronto socorro à população desassistida. Caberia acompanhar o plano desejado e sua implementação, bem como, se a tecnologia colocada em marcha daria conta dessas contradições.

\section{O surgimento de um novo Pronto Socorro: vozes da instituição}

16 RIBEIRO, Maria Alice Rosa. A cidade de São Paulo e a saúde pública, 1554-1954 In PORTA, Paula (org.) História da cidade de São Paulo, São Paulo, Paz e Terra, (307-350), 2004.p.344. 
Para a apreensão desse processo, cabe dar aqui uma breve história do serviço de pronto-socorro paulistano, pois, diferentemente dos serviços criados no Rio de Janeiro (1893) e em Porto Alegre (1898), que se faziam inicialmente em instituições privadas de saúde e, em 1922, passaram à responsabilidade do Hospital do ProntoSocorro do Departamento Nacional de Saúde Pública, em São Paulo, de forma inédita, o serviço ficou sob a responsabilidade da Polícia Civil do Estado:

em 1893, à Segunda Seção da Repartição Central de Polícia estavam subordinados os médicos do serviçolegal, enquanto a Terceira Seção controlava o movimento de indivíduos remetidos ao hospício, asilo e para a Santa Casa de Misericórdia. No mesmo ano, o Decreto 395, de 7 de outubro, deu maior atribuição à Seção Médica, que passou a contar com quatro facultativos, cabendo a cada um deles a incumbência da cadeia da Capital. ${ }^{17}$

Assim, a Assistência Pública dividia-se entre socorros médicos e os que envolviam assuntos de polícia, confluindo numa complexa rede assistencial, envolvendo de atropelamentos a envenenamentos, de picadas de animais a ferimentos por arma de fogo. Exemplarmente, segundo levantamento da Assistência Pública da Capital entre os anos de 1943 e 1944 (de janeiro a novembro), 51.659 socorros foram atendidos, ${ }^{18}$ não necessariamente com a devida resposta ao problema que se apresentava.

Mesmo para as doenças consideradas "apadrinhadas" por políticos, a situação não seria diferente. Conforme indicou Bertolli Filho no caso da tuberculose nos anos $1930-40$, se o prestigio de Adhemar de Barros e de sua esposa, Leonor Mendes de Barros, em propagandas garantia apoio popular e político nas eleições, a

17 SPOSATI, Aldaiza de Oliveira (coord.) A Secretaria de Higiene e Saúde da cidade de São Paulo: história e memória. São Paulo, Departamento de Patrimônio Histórico, 1985. p.130. Brasil, 1944. p.137

18 Boletim do Departamento estadual de Estatística, no. 12, São Paulo, Tipografia 
tendência de crescimento da doença punha tais propagandas sub judice:

o descompasso entre o número de tísicos e as oportunidades de internamento faziam multiplicar as cenas chocantes que feriam o cotidiano da cidade de São Paulo. Nos prontuários médicos, é relativamente comum o registro de casos como o protagonizado pelo carroceiro Henrique Barreiros (P.1875), que, vindo de Iguape, esperou uma vaga hospitalar durante vários meses, sendo que nesse período permaneceu hospedado no Albergue Noturno do município. A data de internamento parecia algo incerto e distante até que, no primeiro dia de dezembro de 1943, o enfermo foi acometido por forte hemoptise quando perambulava nas proximidades da Praça da Sé, momento em que foi socorrido por uma ambulância da Assistência Pública. Em estado préagônico, o tuberculoso finalmente ganhou um leito no pavilhão reservado aos indigentes no Sanatório do Jaçanã. Mas pouco pôde usufruir do tratamento especializado, pois, uma semana após ser recebido no Hospital, Henrique Barreiros chegou a óbito, extenuado pela continuidade de vômitos sanguíneos. ${ }^{19}$

A superlotação da Santa Casa de Misericórdia era a maior expressão dessas limitações, já que quase todos os casos acorriam para lá. Foi nesse quadro que se pensou no hospital que estava sendo construído desde 1938, o Hospital das Clínicas da Faculdade de Medicina da USP (HC-FMUSP), como um novo centro de pronto atendimento. Sua inauguração se deu no dia 19 de abril de 1944, data escolhida por ser também a do aniversário do presidente Getúlio Vargas, dois fatos considerados vultosos e imponentes pela Revista Médico-Social. Entre os presentes, estavam Ademar de Barros,

19 BERTOLLI FILHO, Claudio. História social da tuberculose e do tuberculoso 1900 1950. Rio de Janeiro, Ed. Fiocruz, 2001.p.136. 
interventor que pôs a pedra fundamental da construção do hospital em 1938, e Fernando Costa, o interventor do momento da inauguração:

Os jornais foram pródigos em noticiar a instalação de diversas clínicas, registrando que o hospital ganharia rapidamente capilaridade na assistência e no atendimento, por mio de suas especialidades e laboratórios. Assim, diziam, sucederiam diversas instalações como a Clínica Neurológica, sob comando de Adherbal Tolosa, a Clínica de Urologia, dirigida por Luciano Gualberto, a Clínica Médica de Almeida Prado, somando, em pouco tempo, mais de dez clínicas em funcionamento no hospital, com verba anual de 30 milhões de cruzeiros. ${ }^{20}$

O discurso do diretor da Faculdade de Medicina da Universidade de São Paulo e professor envolvido no projeto do hospital, Benedito Montenegro, foi devidamente publicado. Entre os temas tratados, destacava-se a organização do Pronto-Socorro, inaugurado na mesma ocasião. Mesmo não sendo considerada uma situação definitiva, dizia o Prof. Montenegro que talvez fosse a única aceitável, diante da grave lacuna existente nos serviços de assistência da capital paulista. Esta seção do hospital possuiria 126 leitos destinados aos serviços de pronto-socorro, imediatamente auxiliados pelos clínicos especializados do Hospital. Disse ainda que tal serviço colaboraria principalmente com a Santa Casa de Misericórdia, que via suas atividades nesse serviço sempre improvisadas diante da superlotação: "bastará destacar o número oficial de 7.018 pacientes doentes cujo tratamento foi aí prestado, a requisição da Polícia e da Assistência Pública, durante o ano passado." ${ }^{21}$ Além de contribuir

20 MOTA, André; MARINHO, Maria Gabriela S.M.C. O discurso da excelência em solo paulista - marchas e contramarchas na criação e instalação do Hospital das Clínicas 1916-1950 In MOTT, Maria Lucia e SANGLARD, Gisele (orgs) História da Saúde em São Paulo, Op.cit, (133-170). p.154.

21 MONTENEGRO, Benedito. Discurso pronunciado na inauguração do Hospital das Clínicas em 19 de abril de 1944 In Revista Médico-social, ano II, vol.17, São Paulo. 1944. p.33. 
com a divisão do atendimento dos paciente, as vantagens trazidas pelo Hospital das Clínicas seriam de diversas ordens:

(1) Em primeiro lugar, o Hospital das Clínicas atenderá, em seção própria, aos acidentados da cidade, ministrando-lhes tratamento rápido e adequado, por um corpo de médicos especializados que farão plantão nas respectivas especialidades, ficando cada uma delas a cargo do respectivo catedrático; (2) Evitar-se-á o longo percurso, transitando feridos por seções médicas, antes de chegar ao hospital; este era um dos graves inconvenientes, tantas vezes apontado pelos que discutiram o problema pelas folhas da imprensa; (3) Os doentes serão entregues a um posto especializado, funcionando regularmente, dia e noite, com a única função de atender os acidentados, de que até agora a cidade não dispunha; (4) As autoridades policiais terão um posto de plantão no Hospital das Clínicas, de modo a facilitar a ação da polícia sem retardar o socorro médico de urgência. Essa é uma das características que a nova fase do socorro de urgência da cidade representa, sem dúvida benefícios incalculáveis; (5) Os nossos acadêmicos de medicina, que aqui não tinham oportunidade de ver casos de urgência e que na vida prática iam ser chamados a resolvê-los, com tanta frequência, terão sua aprendizagem agora completada com esse importante setor da vida profissional. ${ }^{22}$

O plano era ambicioso. Por isso, foi apresentado, durante a solenidade de inauguração do hospital, o projeto do Serviço de Pronto-Socorro a ser submetido à aprovação do governo do estado. Com tal intento, o Prof. Godói Moreira, catedrático de Ortopedia e um dos idealizadores do serviço, tratou de alguns temas considerados fundamentais para o bom andamento do Serviço de Pronto-Socorro, a partir da organização de uma clínica especializada dispondo de

22 Idem 
serviços de transfusão de sangue, banco de plasma, serviços de raio $\mathrm{X}$, serviço de clínica médica e cirurgia, serviço de especialidades cirúrgicas, como obstetrícia, oftalmologia e outras, assim como instalações adequadas para o tratamento de fraturas, e tudo isso funcionando em permanência.

Idealizado em todos os pormenores, o HC seria o centro das atividades, onde estariam presentes o serviço hospitalar, o serviço policial e o serviço cartorial. Ambulâncias de prontidão e equipadas responderiam aos chamados por um número de telefone especial:

a cidade vai ser dividida em grandes setores, cada um com seu posto médico e ambulâncias próprias localizadas em pontos estratégicos. Recebido o pedido de socorro no Hospital das Clínicas, duas eventualidades se apresentam: na primeira, o acidente se deu no setor ou nas proximidades do Hospital e, nesse caso, dali mesmo partirá a ambulância com médico da assistência de plantão que recolherá o paciente. $\mathrm{Na}$ segunda eventualidade, o chamado é feito de um bairro distante, o Braz, por exemplo. Do Hospital das Clínicas, o chamado é retransmitido por linhas especiais, reservadas a esse serviço, ao posto mais próximo do local onde se encontra o doente. Desse posto, parte a ambulância com o médico da Assistência, que faz o mais necessário no momento e transporta e confia o caso ao Hospital das Clínicas. ${ }^{23}$

Logo se percebe o quanto o projeto foi inconcluso, desaguando nos mais diversos problemas. $\mathrm{O}$ primeiro deles era $\mathrm{o}$ plano de haver um posto policial em áreas determinadas para que o socorro se pudesse dar conforme a organização esperada. Como publicou o jornal A noite:

Não faz muito tempo que $A$ noite focalizou em ampla reportagem o problema da assistência policial nos bairros

23 Idem, ibidem. p.38. 
além da linha da São Paulo Railway, isto é, Belém, Penha, Braz, Casa Verde e outras grandes concentrações humanas, que representam uma parcela considerável da população da capital. Esse problema que há muito poderia ter sido resolvido com o funcionamento do Pronto-Socorro do Braz, à rua do Hipódromo, em edifício próprio e devidamente equipado, continua na dolorosa categoria dos problemas insolúveis, pois até agora não atende ao público, abrigando-se na sede daquele posto de assistência, inexplicavelmente, uma divisão da Guarda Civil. ${ }^{24}$

Contudo, parece que um dos motivos de tal ineficiência é a oposição que se firmou ao se retirar do posto policial o serviço de pronto-socorro, o que negava os planos objetivados pelo Hospital das Clínicas:

Um dos setores mais eficientes da grande máquina hospitalar e que vem prestando relevantes serviços à coletividade é sem dúvida o Pronto-Socorro do Hospital das Clínicas, que dispõe dos mais eficientes elementos para atingir a sua finalidade, que é prestar assistência a mais variada a casos de urgência, notadamente os acidentados. Essa organização modelar, entretanto, está sendo vítima de uma incúria para qual chamamos a atenção do sr. Secretário da Educação. As pessoas que necessitam de socorro urgente até agora, inexplicavelmente, são transportadas para a Assistência Policial que, como é notório, não dispõe dos recursos exigidos por uma assistência perfeita. E em casos raros pratica-se uma grave irregularidade: leva-se, por conselhos dos funcionários, o enfermo para consultório ou hospital particular, quando o que seria lógico era

24 A noite, São Paulo, 29/08/1945. p.1. 
removê-lo imediatamente para o Hospital das Clínicas, onde seria medicado ou operado imediatamente. ${ }^{25}$

Segundo o contrato firmado, viria da prefeitura a quantia de vinte milhões de cruzeiros para custear os serviços prestados, compreendendo serviços ambulatoriais, cirúrgicos, vítimas de acidentes e crimes, contudo, o não repasse do dinheiro redundou na falta de leitos para $70 \%$ dos doentes em 1951. Em reportagem do jornal $O$ esporte, esse foi argumento seguido da seguinte matéria:

O Hospital das Clínicas foi criado para servir de escola médica para os estudantes da Faculdade de Medicina. Hoje, com a falta de hospitais, excede os limites de sua finalidade, a capacidade servindo de estabelecimento de assistência médico-hospitalar - dispõe de 1.100 leitos, quando já necessita de pelo menos 3.000. Mais de 500 doentes que procuram todos os dias, vindos da capital e do interior, deixam de ser internados por falta de leitos... não há lugar para eles! Qual a causa? A resposta é imediata: falta de verba. E a verba não chega porque cerca de 2 BILHÕES DE CRUZEIROS são desviados anualmente dos cofres públicos por sonegação de impostos. Desse total, quase 250 milhões seriam destinados aos serviços de assistência médico-dentária e hospitalar. Daí o déficit de 300 hospitais, 1.200 maternidades, centenas de creches e ambulatórios em todo o Estado. ${ }^{26}$

As consequências desse processo podem ser acompanhadas na documentação emitida pela Superintendência do Hospital das Clínicas: o problema se avolumava dia a dia, exigindo que o hospital, na figura do superintendente produzisse diariamente dezenas de 
remissivas para dar seguimento à entrada e saída dos pacientes. Vejamos alguns desses documentos:

\begin{abstract}
Meritíssimo Juiz,
Encaminho a Vossa senhoria o menor "desconhecido" do sexo masculino, branco. Foi encontrado pela ambulância central de polícia à rua da Consolação, tendo sido trazido ao pronto-socorro deste hospital por se tratar de recémnascido prematuro. Solicito de Vossa Senhoria as providências que o caso requer, pois o paciente está em alta hospitalar há vários dias, não podendo permanecer neste hospital. $^{27}$
\end{abstract}

Meritíssimo Juiz,

Em resposta ao ofício n. 961, de 30/06/1950, transcrevo abaixo informação prestada ao mesmo Serviço de Arquivo Médico e Estatística deste hospital: o sr. Manoel da Silva Andrade, registro 187857, deu entrada no Pronto-Socorro deste hospital em 02/06/1950, em virtude de agressão por arma de fogo, onde constatou-se: ferimento perfurante do tórax. Ferimento lacerante na região lateral do pescoço. Ferimento lacerante na região mentoniana. Teve alta, curado, em 05/06/1950. ${ }^{28}$

Meritíssimo Juiz de Menores, Encaminho a Vossa Excelência a menor Maria de Souza, com 17 anos de idade, cor prêta, brasileira, filha de Hipólito José de Souza e Maria do Espírito Santo, residente em Xiririca - estado de São Paulo, e já encaminhada a esse Juizado, onde seu número de processo é 1.988. Estando a referida menor em alta hospitalar há vários dias e informando estar só nesta capital, sem residência fixa, solicito de Vossa Excelência as providencia no sentido de que a mesma seja entregue na Seção de Vigilância e Capturas do Departamento de

27 AGUIAR, Enéas de Carvalho Aguiar, Superintendente do Hospital das Clínicas ao Juiz de Menores da Comarca da Capital, Edmond Acar, São Paulo, 06/06/1950. p.543.(remissiva)

28 _ Superintendente do Hospital das Clínicas ao Juiz de Direito da $6^{\mathrm{a}}$. Vara Criminal Eugenio Fortes Coelho 07/07/1950. p.551.(remissiva) 
Investigações, que se encarregará de levá-la para a cidade onde residem seus pais." 29

A crise vivida pelo Pronto-Socorro foi logo narrada com indignação por Enéas Aguiar, o superintendente, numa carta endereçada ao presidente do Conselho da Administração do HC. Sem poupar palavras ou esconder a situação, escreveu, em forma de desabafo, a leitura que tinha sobre todo o processo, suas causas e consequências:

Como no momento procura-se resolver o grave problema do pronto-Socorro nesta capital, com a devida vênia, vimos expor nosso ponto de vista sobre o assunto, objetivando contribuir para a sua solução. De acordo com o Decreto n. 13.899, de 17 de março de 1944, o Hospital das Clínicas a Universidade de São Paulo tem por finalidade, como Hospital de Pronto-Socorro, prestar assistência médica às pessoas portadoras de males súbitos e às acidentadas, necessitando de tratamento de urgência. Este decreto foi cumprido somente na parte que se refere aos tratamentos dos pacientes que necessitam de socorros urgentes. Nunca se conseguiu fazer com que outros dispositivos desse decreto fossem cumpridos: criação do Conselho de Assistência Pública, plantões dos médicos da Assistência Policial, presença de autoridade policial no Hospital, criação de cartório etc. A assistência aos pacientes também deixa sempre a desejar, não obstante a competência dos médicos que trabalham nesse serviço e a dedicação dos servidores do nosocômio. Qual a razão de não ter conseguido que todos os itens do decreto 13.899 fossem cumpridos? A razão é simples: má vontade dos funcionários da Secretaria de Segurança Pública, que se sentiram injustificadamente diminuídos com o mesmo. Qual a razão da falta de assistência eficiente aos pacientes encaminhados ao Pronto-Socorro 
do Hospital? A razão principal é a falta de médico-chefe responsável pelo funcionamento de todas as seções do serviço de Pronto-Socorro [...]. Salvo melhor juízo, podemos afirmar que, sem as medidas que propomos, o P.S. será sempre um serviço onde reinam a anarquia e a pouca eficiência. Como poderá o H.C. pleitear a direção do Pronto-Socorro de toda a capital se até agora não conseguiu tornar eficiente o serviço que funciona há seis anos no seu prédio principal $?^{30}$

\section{Notícias que chegam entre o socorro e o abandono}

Os problemas se acumulavam diante em vários polos: o desmantelamento da máquina administrativa de saúde do município e o descumprimento de acordos sobre a assistência médica e o crescimento vertiginoso do número de pacientes, com diversos graus de complexidade. Também vale lembrar que o descumprimento de acordos ao não se criar um Pronto-Socorro Municipal, matéria que não conseguia ser aprovada na Câmara, desaguou num quadro particular: as pessoas que antes chamavam os médicos em caso de doença passaram a acionar o Pronto-Socorro, canalizando milhares de enfermos e acidentados para o HC. Como o projeto original do hospital não previa esse tipo de serviço, passou-se a usar as enfermarias das especialidades, excedendo sua capacidade de acolher a todos os que procuravam o serviço, como foi o caso do serviço de Neurologia, que atendia ao mesmo tempo 39 casos em outubro de 1951, envolvendo pacientes internados com níveis de gravidade que iam de fratura de crânio a derrame cerebral. ${ }^{31}$ A urgência desse novo pronto-socorro foi largamente tratada pela imprensa, conforme a reportagem a seguir:

30 _ Superintendente do Hospital das Clínicas ao Professor Jayme A. de A. Cavalcanti, (Presidente do Conselho de Administração do HC) 20/11/1950. p.943.(remissiva)

31 O tempo, São Paulo, 19/10/1951. p.2. 
Muito já temos escrito nesta seção sobre os problemas dos socorros de urgência nesta capital; a princípio, em face da extraordinária falta de recursos; depois, ventilando aspectos do plano de criação de postos de emergência, descentralização do primeiro socorro, concentração de serviços hospitalares do Hospital das Clínicas; agora, procuramos chamar atenção para a necessidade da aprovação rápida da lei municipal que cria o Pronto-Socorro Municipal. É do conhecimento de todos a situação antiga, com um único posto de emergência, situado no Pátio do Colégio, que não era mais condizente com o crescimento e a extensão da cidade de São Paulo. Um chamado em Osasco deveria ser atendido por uma ambulância saída do centro da cidade; o mesmo se esse chamado viesse da Penha. Graças aos esforços da Secretaria de Higiene da Municipalidade, foram criados três postos de emergência, com médicos trabalhando gratuitamente em dois, e no outro dando serviços extras, a fim de minorar a situação aflitiva existente. Entretanto, não será possível manter por muito tempo essa situação anômala; os médicos que, demonstrando raro espírito de cooperação, estão trabalhando sem remuneração, não poderão fazer isso por muito tempo. Por outro lado, brevemente, extinguir-se-á o prazo de 90 dias fixado pelo executivo estadual para a transferência dos serviços médicos de urgência para a Municipalidade. O ante-projeto de lei que está na Câmara dos Vereadores consubstancia a opinião média das principais instituições médicas de São Paulo. É preciso que ele seja aprovado dentro do prazo estipulado, para que esta cidade não volte à situação antiga de um único posto central de emergência, no Pátio do Colégio. ${ }^{32}$

Se tal quadro criou uma situação de caos para o hospital, era a população que mais sentia seus reflexos. Cabe destacar um entre os fatos ocorridos: o abandono de pacientes pela cidade por ambulâncias do Hospital das Clínicas, narrada pela reportagem 'Morrer na rua':

32 Diário da noite, São Paulo, 10/06/1951. p.6. 
O Hospital das Clínicas tem enviado constantemente os seus doentes para a Central de Polícia. Quando isso sucede, os infelizes passam a arrastar-se pelos corredores do velho prédio sem quaisquer socorros médicos, uma vez que o Posto de Assistência Pública está desorganizado. Ali há escassez de medicamentos e aparelhos apropriados para a assistência aos enfermos. Assim desprotegidos, não só os seus males se agravam como também vão morrendo lentamente, como tem acontecido algumas vezes. $\mathrm{Na}$ tarde de ontem, parou junto à Central a ambulância de chapa 9-80-97, do Hospital das Clínicas, delas saltando o enfermeiro Rivas Estevan. No momento em que fazia descer do veículo duas enfermas procedentes daquela casa hospitalar, a fim de deixá-las junto à repartição, os médicos Armando Marcondes Machado e Antonio Lanaro, pertencentes ao Abrigo da Central, levaram o caso ao conhecimento do Sr. João Cataldi Junior, primeiro delegado auxiliar. O Sr. João Cataldi Junior determinou que tomassem por termo as declarações do enfermeiro Rivas Estevan e não recebessem as duas senhoras doentes, que são Benedita Teixeira Leite, 23 anos, casada e moradora de Ubatuba, e Francisca de Jesus, 25 anos, solteira, de residência ignorada. A primeira atacada de câncer num dos seios e a outra sofreu recentemente gravíssimos ferimentos num acidente de automóvel. Essas duas mulheres passaram há pouco pelo posto médico da Assistência, de onde foram enviadas ao Hospital das Clínicas, que delas passou a cuidar. Por motivos ignorados, a direção do Hospital deulhes alta, determinando fossem recolhidas à Central de Polícia, que não as pode receber, por falta de materiais adequados ao tratamento das pacientes. O enfermeiro declarou que, se não pudesse cumprir as ordens emanadas da casa hospitalar, abandonaria as doentes em qualquer ponto da cidade. ${ }^{33}$

Outros casos dessa mesma natureza e respondidos igualmente revelavam o drama da população mais vulnerável, vazando pela 
imprensa local outro assunto: o abandono de pacientes pelo Serviço no espaço público. Eram pacientes que, por diversos motivos, eram despejados em ruas e terrenos da cidade:

Não foi atendido no Hospital das Clínicas - Sábado último, às 21 horas, na rua Silva Bueno, no Sacomã, foi atropelado por um jeep o sr. Irineu Nascimento. Transportado para a Assistência, foi a vítima medicada e mandada para casa, com a recomendação de que, se piorasse, voltasse à Assistência, para ser encaminhado ao Hospital das Clínicas. Hoje, segunda-feira, o operário compareceu de novo à Assistência, que o mandou ao Hospital das Clínicas. No grande hospital, entretanto, a vítima não foi atendida, sob a alegação de que o acidente ocorrera havia mais de 24 horas. Sem recursos para um tratamento custeado, necessita da assistência mantida pelo Estado, e não se justifica o verdadeiro jogo de empurra estabelecido entre o plantão, a Assistência e o Hospital das Clínicas. ${ }^{34}$

Agravando esse processo, a falta de assistência social também ensejou narrativas sobre as necessidades de quem procura o hospital e os desdobramentos dessas necessidades. Um desses casos foi publicado sob o título de "Monstruosidade":

um caso doloroso foi comunicado à reportagem de $A$ noite, que imediatamente se dirigiu ao local indicado para apurar a sua procedência. Na rua Conselheiro Nébias, esquina com a rua Helvétia, um moço com a perna quebrada tinha sido despejado de uma ambulância. Contou ele que teve uma perna esmagada por um bonde e, socorrido por uma ambulância da Assistência Policial, foi removido ao Hospital das Clínicas, onde ficou internado, recebendo tratamento adequado. Oito dias

34 Folha da noite, São Paulo, 11/09/1947. p.7. 
depois, porém, disseram-lhe que ele teria alta e iriam levá-lo para casa. Hermínio respondeu que não poderia ir para casa pelo simples fato de não ter residência e nem família em São Paulo. E anteontem, quando menos esperava, foi colocado numa ambulância e levado até a rua Conselheiro Nébias, esquina com Helvétia. Ali, a ambulância parou e despejou o pobre moço junto aos tapumes da construção. Lá está ele, sem ter para onde ir e sem poder andar. ${ }^{35}$

Outro caso de abandono de paciente, que mereceu atenção da imprensa, indicaria um misto de problemas que envolviam parte da população, onde a falta de moradia servia como ingrediente para as dificuldades de solução de casos de adoecimento grave e urgente:

Falta de humanidade - Maria Barbosa da Silva tem agora 61 anos. Vive num barracão nas proximidades do Jaçanã. Por duas vezes, esteve internada no Hospital das Clínicas, sendo a última em 1945. Sofre de perturbação gastro-intestinal e das faculdades mentais. Agora encontrava-se mal novamente. Waldomiro Atamanzuk, no dia 22 passado, conseguiu que ela fosse internada nas Clínicas. Mais tarde, telefonou ao hospital, procurando saber do estado de Maria Barbosa, tendo ciência então de que ela recebeu alta. Como achasse isso impossível, começou a procurá-la pelas proximidades do barraco, indo encontrá-la abandonada no meio do mato, tendo como única companhia o seu cãozinho Gibi. Waldomiro regressou ao Hospital das Clínicas procurando saber quem fora o responsável por tamanha desumanidade. Quase chegaram a escarnecer de seu gesto. Revoltado, procurou nossa Redação, levando-nos até o local, onde, protegida dos raios ardentes do sol por folhas de jornal e vegetais, jazia a infeliz, cuja doença consome lentamente. 
A doente, com auxílio da reportagem, foi internada no Hospital da Santa Casa de Misericórdia. ${ }^{36}$

Contudo, se a documentação apresentada já mostrava os limites de um projeto quase malogrado diante de sua proposta original, por outro lado, ganhava novo relevo quando de fato os pacientes passaram a registrar o dia a dia vivido dentro do Serviço de Pronto Socorro. Foi assim que, em 1956, foi aberto um livro de queixas, onde pacientes, que sabiam escrever, registrariam suas experiências. O objetivo da instituição era de captar na ponta do sistema questões que poderiam ser, de alguma forma, equacionadas como, por exemplo, o que diz Geraldo Idalino Moreira, morador da Chácara Glete:

Trouxe minha filha Alaide Gomes Moreira, que passou a noite toda com febre. Cheguei ao Pronto-Socorro às 5:50 da manhã, sendo atendido pelo Registrante, que fez a ficha da minha filha imediatamente, dizendo-me, após preencher a ficha, que eu deveria esperar até às 7:00hs, pois os médicos estavam dormindo, só vindo atender casos muito graves. Declarei que o caso de minha filha era grave. Esperei até 7:00hs como determinou o funcionário e como nessa hora minha filha não foi, falei com o funcionário que estava pelo saguão (por volta das 7:30hs) o professor me respondeu: “- o senhor tem pressa? É melhor ir para a Santa Casa, pois lá também tem Pronto-Socorro". Foi-me também informado por funcionários de plantão no Registro que eu teria de esperar até 8:00hs, quando entrassem os outros médicos de plantão. Vim então fazer essa reclamação porque não 
acho justo o que fizeram com minha filha. Geraldo Idalino Moreira. $^{37}$

A resposta do Hospital, nesse caso, mais uma vez, se somava a situação que vinha sendo narrada, quer pela Superintendência, quer pela imprensa. Falaria, pelas entrelinhas do discurso oficial, das dificuldades que abarcaram a questão e prometia-se as averiguações necessárias para o caso, porém, como pode se acompanhar esse não seria um fato isolado, mas apenas mais um a ser computado dentre tantos outros vivos pela população em busca de assistência:

- Resposta do Hospital: Imediatamente após tomar conhecimento da reclamação, dei ciência da mesma ao senhor Superintendente, o qual mandou-me até o ProntoSocorro para tomar as devidas providências. No ProntoSocorro, verifiquei que a mesma Alaide estava sendo atendida naquele momento (8:00hs) pelo Sr. Dr. Paulo Eiró, médico pediatra. Tomei informações com funcionários do Registro de Pronto-Socorro, os quais informaram que havia certa dificuldade nesse período da manhã (5:30-8:00hs) devido à troca de plantão dos médicos. À ordem do senhor Superintendente, convoquei o sr. Laurici Melotti, funcionário do Registro do ProntoSocorro, para prestar informações."

\section{Uma história inacabada...}

A situação desenhada pelo Serviço de Pronto Socorro do Hospital das Clínicas em seus primeiros anos aprofundou-se nos próximos anos. De fato, havia um descompasso entre a formulação 1982), São Paulo, 09/03/1956. p.2.(manuscrito) 
original e a própria gestão da cidade de São Paulo, que se moveu pouco no sentido da descentralização de suas unidades voltadas para esse tipo de ação médica, trazendo pacientes acima do suportado pelo hospital, não apenas da cidade de São Paulo, mas de toda a área metropolitana, colocando suas atividades muitas vezes sob colapso.

Indo além, as conjunturas futuras que viriam se somar à situação, exemplarmente do período militar, colaboraram para colocar tal serviço em suspeição por outra ordem. Segundo relato de expresos políticos, houve uso frequente do Serviço de Pronto Socorro para recebê-los após sessões de tortura. Para alguns, haveria médicos e funcionários que buscaram no pronto atendimento e, dentro das possibilidades possíveis, formas de sua proteção, mas há também outros que relatam a participação daqueles e daquelas que seriam responsáveis em deixa-los 'nas condições ideais' para o prolongamento dos interrogatórios e das mesmas sessões. Os anos de 1980, com o processo de redemocratização do país e de suas instituições, inclusive as hospitalares, o Complexo Hospitalar HC sofreu em 1983 uma reforma de seus serviços como resposta à situação que vigia, entre eles, o de seu Serviço de Pronto Socorro, que se não equacionou de forma definitiva seus problemas de demanda, trouxe, sem dúvida, concepções alternativas de acolhimento e gerenciamento de suas atividades. Enfim, uma história que ainda não acabou.

Ao fim e ao cabo, o estudo aqui apresentado indica os caminhos da institucionalização médica e de saúde na cidade de São Paulo, cheio de rupturas e solavancos, mas também para um fato fundamental: que as formas de adoecimento têm história. Nessa perspectiva, Marc Ferro falará dos 'sintomas' sociais das doenças produzidas pela ideologia do progresso, justamente, pela combinação de um estado considerado clínico de desvio frente ao sistema político e socioeconômico infligido, conflito que, aparentemente, havia sido transposto há tempos atrás:

Ontem, esses conflitos situavam-se na relação de exploração do homem pelo homem, e exprimiam-se antes de tudo nos movimentos coletivos; hoje, a doença parece ter tomado o lugar da greve, ou conjuga-se com ela (em 
alternância ou não) como forma de recusa social. A doença tão depressa se manifesta como uma forma de resistência passiva à organização do trabalho, à injustiça e à desigualdade; tão depressa, pelo contrário, como um efeito da desorganização do trabalho, da insegurança, da pressão que a situação atual exerce. ${ }^{38}$

RECEBIDO EM: 01/03/2017 APROVADO EM: 01/06/2017 